\title{
Mídia e subjetividade: impacto no comportamento alimentar feminino
}

\section{Media and subjectivity: impact on female feeding behavior}

Angela ANDRADE ${ }^{1}$

Maria Lúcia Magalhães BOSI²

\section{RES U M O}

Este ensaio analisa alguns dos subprodutos do processo de globalização, tais como a massificação e a importação de modelos culturais hegemônicos, os quais destituem o homem do sentimento de pertença a grupos humanos e invadem seu universo simbólico, expropriando o centro de referência cultural balizador do psiquismo humano. Nessa fratura desalojadora de significação humana e que se sustentam algumas doenças modernas e emergentes, como os Transtornos do Comportamento Alimentar, problemática que se expressa no campo da Saúde Pública como uma epidemia silenciosa e simbólica, nesta virada de milênio.

Termos de indexação: alimentação, nutrição, conduta na alimentação, saúde pública, transtornos do comportamento alimentar.

This essay analyzes some of the by-products of the process of globalization, such as the massification and the importation of hegemonic cultural models, which strip man of the feeling of belonging to human groups and invade his symbolic universe. This condition expropriates the cultural point of reference that forms the basis and structures the human psyche, causing generalized distress. This fracture dislocates the human identity and sustains some modern and emerging diseases, such as feeding behavior disorders. This problem is expressed in the area of Public Health as a silent and symbolic epidemic at the turn of the millennium.

Index terms: feed, nutrition, feeding behavior, public health, feeding behavior disorders.

\footnotetext{
1 Departamento de Saúde Comunitária, Faculdade de Medicina, Universidade Federal do Ceará. R. Prof. Costa Mendes, 1608, 5a andar, 60430-140, Rodolfo Teófilo, CE, Brasil. Correspondência para/Correspondence to: A. ANDRADE. E-mail: angelaandrade@uol.com.br

2 Núcleo de Estudos em Saúde Coletiva, Faculdade de Medicina, Universidade Federal do Rio de Janeiro.
} 


\section{N T R O D U Ç Ã O}

Estamos vivenciando o início de um novo milênio, testemunhando a chamada Terceira Revolução Industrial, época de grandes e profundas transições, estruturalmente vinculada à globalização, que impulsiona países como o Brasil a aderir à comunidade internacional, de modo a garantir sua sobrevivência em uma economia globalizada, na qual as regras do mercado são estabelecidas pelos grandes conglomerados financeiros.

Rattner (1995) descreve as origens dessas megatendências e deposita as forças mais ativas e poderosas do processo da globalização na voracidade do capital transnacionalizado, acumulativo e especulativo que cresce estrategicamente, garantindo, com este movimento predatório, altas taxas de lucratividade e a acumulação de $40 \%$ de toda a riqueza mundial. Desse modo, elites se tornam cada vez mais poderosas enquanto os pobres se vêem excluídos do sistema e dos benefícios sociais básicos, dentre eles, o acesso aos serviços de saúde, trabalho, educação, lazer.

Apesar das muitas mudanças verificadas no Brasil, nas últimas décadas, uma realidade se mantém estável: o país continua sendo caracterizado por ter uma distribuição de renda das mais desiguais do mundo. Segundo Rigotto (1998), esse cenário, longe de estar restrito ao plano econômico, envolve as esferas política e cultural, acarretando a diluição de fronteiras e enfraquecendo o Estado Nacional.

Claro está que a Reestruturação Produtiva é um processo econômico, político e cultural em curso, de grande dinamismo e alta complexidade, que acontece em escala planetária em ritmo intenso, exigindo a inserção de todos. Estruturalmente vinculada à Globalização, estes dois processos têm sido conduzidos pelas forças hegemônicas a nível internacional, representando a mais recente configuração do capitalismo - a qual converte o sistema mundial em espaço de acumulação - apontando para profundas repercussões sobre a vida social (Rigotto, 1998, p.3-4).

Uma fragmentação simbólica advém da insustentabilidade desse processo, da perda de valores culturais que dão referência à construção de subjetividades. A importação de modelos globais, em todas as dimensões da vida humana, pulveriza a dimensão simbólica, de forma violenta, transformando os modos de produção, de hábitos, de valores, e outros, promovendo um desenraizamento cultural, gerando um mundo de incertezas e de riscos produzidos, o qual se desdobra na perda da liberdade e da identidade humana.

Hall (2000) propõe a categoria analítica "descentração do sujeito pós-moderno", ilustrando o caminho através do qual se estabelece uma crise de identidade no homem contemporâneo. Aponta algumas concepções de identidades que foram se conjeturando do lluminismo à atualidade, imersas na onda da revolução tecnológica. De uma identidade anteriormente unificada e estável pelas raízes do tradicionalismo, assiste-se a um deslocamento para outra descentrada, resultante de mudanças estruturais e institucionais. Assim, "dentro de nós há identidades contraditórias, empurrando em diferentes direções, de tal modo que nossas identificações estão sendo continuamente deslocadas" (Hall, 2000, p. 13).

Em contexto como o do Brasil, nosso cotidiano é cada vez mais influenciado por valores externos à nossa cultura, importados dos países economicamente dominantes. O imediatismo das transformações, conseqüente da diminuição das distâncias ocasionada pela revolução dos meios de comunicação e de transportes, faz com que, ao adquirirmos um bem de consumo, as repercussões cheguem a afetar desde a divisão internacional do trabalho até certas determinações no ecossistema da terra (Carvalho, 1997).

Conforme adverte Giddens (1991), a globalização não deve ser vista simplesmente como a intensificação das relações sociais em escala mundial, na medida em que integra 
diferentes contextos sociais. Esse movimento, geralmente, figura de maneira insidiosa e silenciosa, transforma espaços locais e, por conseguinte, afeta as intimidades da existência pessoal, pois atua de forma a modificar a vida cotidiana.

Com efeito, o projeto da modernidade, ancorado no cientificismo e no tecnicismo, alcançou uma velocidade vertiginosa, adoecendo o meio ambiente e a humanidade, os quais não conseguem acompanhar o seu ritmo intenso e avassalador, apontando, assim, na mesma ordem exponencial de crescimento, os seus limites. A racionalidade, como um dos pilares deste projeto moderno, produz uma avalanche de números que em muitas vezes banaliza os problemas, e oculta o sofrimento humano (Rigotto, 1998).

Um conjunto de rápidas transformações na esfera técnico-científica, na racionalização dos processos de produção e na modernização dos meios de comunicação dilui nosso sentido de identidade e coletividade. A desterritorialização é mais evidente no plano econômico, na medida em que testemunhamos a dispersão dos meios de produção; não se tem mais um ponto de referência exato, "tudo" é mundial e em trânsito, através das redes digitalizadas de transações comerciais. Há uma descorporificação e, conseqüentemente, uma virtualização do mundo do trabalho. Desta forma, quando compramos um produto não sabemos mais os limites geográficos de sua fabricação, pois a matéria-prima, a produção e a distribuição se encontram em territórios distintos. Assim é o reino das Corporações Transnacionais, cuja preocupação eminente é: gerar necessidades de consumo (Hall, 2000).

Compreendemos a desterritorialização, aqui referida no contexto do trabalho, como um fenômeno a se infiltrar nas mais diversas áreas da existência humana, descentrando subjetividades e, também, gerando inseguranças e desigualdades. De fato, esta vulnerabilidade, como conseqüência de um fenômeno social, poderá se traduzir em uma busca humana de referentes, a fim de balizar a construção de um sentido de "ser-no-mundo", que por ora, vem se fragmentando (Hall, 2000).

De acordo com Costa (1999), o ser humano recorre ao corpo como critério de identidade. $O$ individualismo narcísico e hedonista elege o corpo e as sensações como os depositários dos valores pessoais na atualidade. Com o apogeu da racionalidade científica moderna, a humanidade passou a acreditar que deveria controlar o desgaste biológico, não deveria envelhecer e poderia deter o controle da morte, aumentando a longevidade. Nossa cultura passou a banalizar a morte, da forma como é teatralizada na TV, através do extermínio do outro em um palco onde predominam excentricidades e, sobretudo, violência.

Nesse panorama, lugar da virtualidade, dos ícones e imagens globais, uma trama plural com múltiplos eixos problemáticos, não há tempo para lidar com a nossa grande e única certeza - a finitude humana; desviamo-nos da idéia de morte com a supervalorização do corpo e das sensações, para não refletir sobre o fim do tradicionalismo, da espontaneidade e da liberdade criadora, abortados por este projeto da contemporaneidade; deparamos-nos, então, com a perda da identidade (Costa, 1999).

Essa cultura da sensação é o esteio pelo qual se difunde a pseudoverdade de que a felicidade e o conhecimento são adquiridos, principalmente, através do âmbito restrito do consumo, perfilando a esta lógica massivos investimentos na produção da imagem corporal feminina. Assim, o corpo e todo o instrumental utilizado para projetá-lo como símbolo de poder passam a ser perseguidos como bens simbólicos, na tentativa de neutralizar o mal-estar gerado pela fragmentação da identidade; daí decorre o excesso de investimentos da mídia com temas relacionados à beleza e à aquisição do corpo perfeito, em campanhas geralmente acom- 
panhadas de imagens da mulher moderna, atrelando a elas, de forma subliminar, sucesso, felicidade, dinamismo, bem-estar pessoal, e outras características dotadas de simbolismo (Costa, 1999).

Nesse contexto, como compreender o comportamento obsessivo com a alimentação e o medo de engordar, que leva milhares de mulheres a comer compulsivamente ou adotar dietas restritivas e até morrer de fome mesmo diante da fartura de alimentos?

\section{O IDEAL DE IMAGEM \\ COR P OR A L: A L G U S \\ ELEMENTOS EM JOGO \\ NA SUA CONSTITUIÇÃO}

Autores como Kutscka (1993), Nunes (1997) e Cordás (1998) discutem a importância na patogênese dos transtornos alimentares dos fatores socioculturais que impõem um ideal de beleza, juntamente com o culto às dietas hipocalóricas e ao corpo esquálido. Com efeito, se observarmos a evolução dos padrões de beleza, desde a Vênus de Milo e os quadros de nus dos pintores do século XVI ao início do século $X X$, constatamos um processo de construção da imagem caquética feminina materializada nas manequins que, a partir da década de 60 até a atualidade, vêm assumindo antropometrias cada vez menores.

Nas sociedades ocidentais contemporâneas, o preconceito contra a obesidade é, sem dúvida, muito forte. O culto à magreza está diretamente associado à imagem de poder, beleza e mobilidade social, gerando um quadro contraditório, "esquizofrenizante", tendo em vista que, através da mídia escrita e televisiva, a indústria de alimentos vende gordura, com o apelo aos alimentos hipercalóricos, enquanto a sociedade cobra magreza.

O ideal de corpo perfeito preconizado pela nossa sociedade e veiculado pela mídia leva as mulheres, sobretudo na faixa adolescente, a uma insatisfação crônica com seus corpos, ora se odiando por alguns quilos a mais, ora adotando dietas altamente restritivas e exercícios físicos extenuantes como forma de compensar as calorias ingeridas a mais, na tentativa de corresponder ao modelo cultural vigente. Dessa forma, aumenta-se a pressão da equação: promessa de Felicidade e Beleza = Consumo (Kutscka, 1993).

No tocante a essa problematização, acredita-se que o atual momento histórico fomenta no imaginário feminino a fantasia de que só basta querer para adquirir a imagem corporal idealizada. O avanço da tecnologia da beleza, através do apelo midiático-imagético, o qual modela subjetividades e impulsiona o lucrativo mercado da indústria da magreza, coopta o simbólico feminino em suas necessidades básicas, seduzindo-o para o alcance do corpo perfeito. Para tanto, publiciza, via fascinação, modelos de beleza que tendem a ocupar o limite extremo dessa busca obsessiva, desfigurando, assim, a tênue linha divisória entre o saudável cuidado com o corpo e o sutil movimento de instalação de doenças narcísicas.

A insatisfação crônica com a imagem corporal, entre outros fenômenos, exemplifica o insidioso percurso que tende a colocar a mulher em uma busca militante pela beleza. Na verdade, estabelece-se, assim, na esfera da subjetividade, um autêntico conflito contra uma certeza que nos é inalienável: nossos limites humanos (Minerbo et al., 1997).

A análise desse processo demarca sua gênese no início do século $X X$, mas encontra suas raízes no esteio da Revolução Industrial, quando os meios de produção e poder se deslocaram das mãos da aristocracia rural para a classe burguesa, impondo, concomitantemente, uma estrutura de comunicação massiva para a divulgação da informação. Apareceram as primeiras revistas femininas, ligando a imagem da mulher ao confinamento domiciliar.

À medida que a mulher, a partir da década de 60, foi conquistando espaço no mercado de 
trabalho, legitimando a sua emancipação, tendo direito ao voto e ao uso da pílula anticoncepcional, estabeleceu-se um novo paradoxo: a mulher passou, então, a enclausurar-se no próprio corpo sob a égide do mito da beleza. De certa forma, aprendemos a ter uma visão distorcida da beleza, em virtude de a mulher ser maciçamente exposta aos padrões corporais atuais, incorporando essa imagem específica e aprendendo a gostar dela. Em outras palavras, estamos tão acostumados a ver como modelo mulheres extremamente magras que aprendemos ser esse o padrão de beleza (Wolf, 1992; Swift, 1997).

O consumismo, o hedonismo e o narcisismo - marcas legítimas da cultura moderna - movem bilhões de dólares e fazem do Brasil o campeão em cirurgias plásticas por motivos estéticos (Sociedade Brasileira..., 1999) e o maior importador de femproporex, uma substância anorexígena (Centro Brasileiro..., 1998).

Andrade \& Costa (1999) analisam os efeitos nocivos do uso deliberado de anorexígenos, os quais fazem parte desta lógica lucrativista da cultura de "sensações". Prescritos pela classe médica através de fórmulas produzidas em farmácias de manipulação, ou através de produtos manufaturados pelas grandes indústrias farmacêuticas, destinam-se a pessoas que desenvolvem quadros de obesidade e/ou transtornos do comportamento alimentar, constituindo estes últimos uma realidade emergente e oculta, na Saúde Pública do Brasil.

Dados publicados apontam o aumento do número de adolescentes submetendo-se a operações plásticas por motivos estéticos; segundo a Sociedade Brasileira de Cirúrgia Plástica, os números dobraram de 1997 a 1998 (Sociedade Brasileira..., 1999). Diante disso, indagamos: o amadurecimento e a emancipação feminina estão associados, concretamente, a um ganho efetivo em termos do controle que as mulheres exercem sobre seus corpos? Que fatores influenciam esta relação? Qual o papel da mídia nesse contexto?

\section{M Í D I A, S U B JETIVID A D E E COMPORTAMENTO A L I M E N T A R}

Bourdieu (1997), analisando os efeitos nocivos da televisão sobre o imaginário social, tece duras críticas a este mecanismo de "fabricação de subjetividades", conjeturado sob a forma de um campo, espaço socialmente estruturado como produtor de violência simbólica, onde ocorrem as lutas de poder para sua transformação ou conservação; nele se desdobra a pressão das macroestruturas econômicas e sociais, outorgando relações concorrenciais e desleais, sendo, verdadeiramente, um espaço de exclusões e invasões. Na medida em que a mensagem veiculada é unidirecionada para o interlocutor, não há via dialógica e sim impositiva.

O autor ressalta, ainda, o "fast-food cultural" no qual vivemos, com as informações sendo veiculadas sob a urgência do tempo, alertando que, nessa velocidade, não há tempo suficiente de assimilação pelo desdobramento do pensamento. Com isso, a comunicação é instantânea, porque, em certo sentido, ela não existe, pondo em pauta de análise as forças invisíveis e coercitivas por trás da produção no imaginário:

Não vou entrar nos detalhes da análise das estruturas invisíveis - que são um pouco, como a força da gravidade, coisas que ninguém vê mas é preciso supor para compreender o que se passa - às experiências individuais, isto é, como relações de forças invisíveis vão se retraduzir em conflitos pessoais, em escolhas existenciais (Bourdieu, 1997, p.75).

Um fragmento do pensamento de Platão é referenciado por Bourdieu (1997), quando afirma que "somos marionetes da divindade", visando traduzir o poder da televisão, através de seus agentes sociais, na criação de valores míticos como liberdade, autonomia, felicidade 
e bem-estar, prescrevendo, simultaneamente, comportamentos adequados ao alcance de tais fins.

Para dimensionar essas reflexões na realidade do Brasil, podemos analisar nossa posição consoante as reflexões de Bourdieu. Segundo dados da Pesquisa Nacional por Amostra de Domicílios (1996), 86,2\% da população brasileira possui televisores em seus lares e 90,3\% possui rádio, bens de consumo que assumem a liderança da pesquisa, enquanto o item geladeira ocupa o 5o lugar, com 80,3\% . Diante dessas informações, podemos observar a existência de brasileiros que dão preferência à aquisição de meios de comunicação nos seus lares em detrimento de outros bens de consumo, considerados como necessários à rotina e à manutenção básica de uma família.

Transladando as reflexões até aqui apontadas para a discussão da influência da mídia na produção do ideal de beleza feminina, observamos a disseminação de duas crenças falsas acompanhando a busca do corpo ideal. Uma delas é a de que o corpo é infinitamente maleável, podendo alcançar o ideal estético com dietas e exercícios, negligenciando-se as determinações biológicas e genéticas, situação chamada por alguns autores, na literatura especializada, de setting point (Cordás, 1998; Nunes et al., 1998). Para este intento, é necessária uma grande dose de esforço pessoal, acompanhado de conotações simbólicas de sucesso, liberdade, felicidade, longevidade, liberação sexual, mobilidade social, e outras, reforçando a outra crença de que, ao conseguir este ideal, a pessoa terá alcançado o sucesso não só na profissão como também nos relacionamentos sociais e amorosos (Azevedo, 1996 Azevedo \& Morgan, 1998a; Strasburger, 1999).

Azevedo \& Morgan (1998b) adverte-nos que, ao realizarmos análises voltadas à influência da mídia na produção das imagens femininas, é preciso ter os devidos cuidados para não cairmos em posições reducionistas quando a mídia e a tecnologia das informações consolidam o movimento da globalização. Para tanto, devemos considerar que a importação de modelos fragmenta e dilui as fronteiras nacionais, despersonifica a cultura de um povo, infiltrando sentimentos conflitivos em relação à identidade cultural, pulverizando-a tanto no plano individual quanto no coletivo, neutralizando o sentimento de pertença a um grupo ou comunidade, tão vital para a garantia da saúde.

O refúgio ante tal expropriação se dá através da instalação de comportamentos patológicos que, com o aumento das expectativas voltadas ao papel da mulher, produzem demasiada insegurança, vulnerabilizando sua identidade, levando-a, na tentativa de resgatar a integridade de sua existência, a buscar, no próprio corpo, o controle perdido.

Em semelhante análise, Guattari (1990) denuncia o esfacelamento de subjetividades ancoradas pelas formas de produção da vida moderna, pelas rápidas transformações técnico-científicas e pelos avanços dos meios de comunicação, os quais engendram no cotidiano formas cada vez mais expropriadas de si, através do ritmo frenético imposto pelo modo imperialista do capitalismo mundializado. Observa-se o abandono progressivo de uma economia voltada para a produção de bens de consumo e serviços em favor da produção de imagens, símbolos e sintaxes, por intermédio, especialmente, do controle que exerce sobre a publicidade e as sondagens, alienando, massificando e normalizando o modelo global.

\section{O N CLUS Ã O}

Nesse árido universo, movido por interesses hegemônicos, que manipulam e produzem "violência simbólica", não há espaço para valores como humanidade, solidariedade e bem-estar coletivo. As doenças são cada vez mais avassaladoras e as indústrias farmacêuticas 
se tornam cada vez mais poderosas no Ocidente. É o mundo dos paradoxos, das desigualdades, do desemprego estrutural; é o mundo globalizado, no qual convivemos com a barbárie dentro das nossas casas, com as mutilações, com os fuzilamentos coletivos e com os sobressaltos da possibilidade de uma Terceria Guerra Mundial; e o mundo do crack e do êxtase; é o mundo da inversão de valores entre o público e o privado. Valores como igualdade, fraternidade e liberdade dão lugar ao individualismo de uma cultura de sensações em que o ser humano perde sua identidade (Costa, 1999).

Em síntese, podemos dizer que esses fatores são o "envelope cultural" dos transtornos do comportamento alimentar, em suas diferentes modalidades - anorexia, bulimia, transtornos alimentares não específicos. Com efeito, os quadros de anorexia (restritiva e/ou purgativa) e bulimia (purgativa e/ou sem purgação) apresentam-se intimamente relacionados por manifestarem psicopatologia comum: uma idéia prevalente envolvendo a preocupação excessiva com o peso e a forma corporal, expressa como um medo mórbido de engordar (Azevedo, 1996; Hercovici, 1997; Hercovici \& Bay, 1997; Buckroyd, 2000). Em ambos os casos, a baixa auto-estima e a insatisfação com a imagem corporal são fatores de risco para transtornos alimentares, levando a um julgamento de si indevidamente baseado na forma física, cuja avaliação se encontra comprometida por uma distorção cognitiva da percepção da auto-imagem, debilitada por práticas inadequadas de controle de peso e comportamentos alimentares anormais (Fairburn et al., 1997; Fairburn et al., 1999).

Esses quadros constituem, hoje, uma "epidemia silenciosa" (Bosi, 1998) - talvez por isso, ainda não reconhecida pelas políticas públicas no setor da saúde - cuja eclosão estamos presenciando neste início de milênio, e cuja essência guarda em si uma complexidade de dimensões apontando na legitimidade de sua dor psíquica as determinações da dor somática (Andrade \& Bosi, 1998).

O corpo passa a ser o canteiro dos rituais obsessivos que levam indivíduos a negar suas necessidades básicas, lançando-se em um círculo vicioso e obsessivo entre dietas restritivas, jejuns prolongados e rígidos controles sobre a ingesta, o corpo e a imagem corporal (Robell, 1997). A outra face do espelho, refletindo o caos nutricional (Andrade, 1998), revela-se por períodos de orgias alimentares, binge-eating, para em seguida forçar o vômito e ingerir laxantes e diuréticos de forma abusiva, na busca incessante pela magreza.

Estamos falando de quadros considerados como "transtorno mental" responsáveis, em certas modalidades, pela maior taxa de letalidade, 20\% (Nunes \& Ramos, 1998) entre todos os tipos de morbidades psíquicas, levando à morte, basicamente, por desnutrição, suicídio e parada cárdiorrespiratória (Sociedade Brasileira..., 1993).

\section{REFERÊ NCIAS BIBLIOGRÁFICAS}

ANDRADE, A.C. Doutor, minha filha parou de comer! Aspectos psicopatológicos dos distúrbios alimentares. Desafios para a prática clínica da nutrição. In: JORNADA DE NUTRIÇÃO DA UNIVERSIDADE FEDERAL FLUMINENSE, 7., 1998, Rio de Janeiro. Comunicação Oral. Rio de Janeiro, 1998. 15p. (Mimeografado).

ANDRADE, A.C., BOSI, M.L.M. Distúrbios alimentares en el Tercer Mundo: una realidad emergente en el panorama de la Salud Pública en Brasil. In: CONFERENCE OF THE INTERNATIONAL ASSOCIATION OF HEALTH POLICY, 10., 1998, Perugia, Italia. Proceedings... Perurgia, Itália, 1998. p.1.

ANDRADE, A.C., COSTA, A.C. Transtornos alimentares e obesidade e o uso deliberado de anorexígenos: uma realidade social oculta na Saúde Pública do Brasil. Fortaleza, 1999. 
Mestrado (Saúde Pública). Universidade Federal do Ceará, 1999. (Mimeografado).

AZEVEDO, A.M.C. Programa de Transtornos Alimentares do Departamento de Psiquiatria e Psicologia Médica UNIFESP/EPM [online]. São Paulo, 1996. Disponível na Internet: <www.polbr.med.br/ arquivo/angelica.htm>. Acesso em: 6 mar. 1997.

AZEVEDO, A.M.C., MORGAN, C.M. Notas sobre a oitava Conferência em Transtornos Alimentares - New York [online]. São Paulo, 1998a. Disponível na Internet: <www.polbr.med.br/arquivo/ tralimen.htm>. Acesso em: 6 out. 1998.

AZEVEDO, A.M.C., MORGAN, C.M. Aspectos Socioculturais dos Transtornos Alimentares - New York [online]. São Paulo, 1998b. Disponível na Internet: <www.polbr.med.br/arquivo/cuture.htm>. Acesso em: 6 out. 1998.

BOURDIEU, P. Sobre a televisão: seguido de: a influência do jornalismo e os jogos olímpicos. Rio de Janeiro : Zahar, 1997. 143p.

BUCKROYD, J. Anorexia e bulimia. São Paulo : Ágora, 2000. $136 \mathrm{p}$.

BOSI, M.L.M. Transtornos do comportamento alimentar: uma questão para a Saúde Pública? Rio de Janeiro : Nesc/UFRJ. 1998. (Mimeografado).

CARVALHO, A.M.P. O Processo de globalização e seus rebatimentos no Estado. In: I CONGRESSO DE ASSISTÊNCIA SOCIAL DA AMAZÔNIA, 1997, Belém, PA. Comunicação Oral. Belém, PA 1997. 21 p. (Mimeografado).

CENTRO Brasileiro de Informação sobre Drogas Psicotrópicas. Boletim Informativo São Paulo, 32, 1998.

CORDÁS, T.A., COBELO, A., FLEITLICH, B., GUIMARÃES, D.S.B., SCHOMER, E. Anorexia e bulimia: o que são? Como ajudar? Um guia de orientação para pais e familiares. Porto Alegre : ArtMed, 1998. 59p.

COSTA, J.F. O Humanismo ameaçado. Jornal do Brasil. Rio de Janeiro, caderno B, 24 jan. 1999. p. 1.

FAIRBURN, C.G., WELCH, S.L., DOLL, H.A., DAVIES, B.A., O'CONNOR, M.E. Risk factors for bulimia nervosa. Arch Gen Psychiatry, Oxford, v.54, p.509, 1997.
FAIRBURN, C.G., ZAFRA, C., BONECA, H.A., WELCH, S.L. Risk factors for anorexia nervosa: three integrated case-control comparisons. Arch Gen Psychiatry, Oxford, v.56, p.468, 1999.

GUATTARI, F. As três ecologias. São Paulo : Papirus, 1990. 56p.

GIDDENS. A. As conseqüências da modernidade. São Paulo: Unesp, 1991. 177p.

HALL, S. A identidade cultural na pós-modernidade. Rio de janeiro : DP\&A, 2000. 102p.

HERCOVICI, C.R., BAY, L. Anorexia nervosa e bulimia. Porto Alegre: Artes Médicas, 1997. 184p.

HERCOVICI, C.R. A escravidão das dietas. Porto Alegre: Artes Médicas, 1997. 181p.

KUTSCKA, H.J. O consumo do belo. In: CORDÁS, T.A. Fome de cão. Quando o medo de ficar gordo vira doença: anorexia, bulimia e obesidade. São Paulo : Maltese, 1993. p.103-110.

MINERBO, M., KHOURI, M.G., AJZENBERG, R., GRUNBERG, S. Beleza feminina: um tema da clínica contemporânea. Revista Brasileira de Psicanálise, São Paulo, v.31, n.3, p.809, 1997.

NUNES, M.A.A. Prevalência de comportamentos alimentares anormais e práticas inadequadas de controle de peso em mulheres de 12 a 29 anos em Porto Alegre. Porto Alegre, 1997. 102p. Dissertação (Mestrado em Epidemiologia) - Faculdade de Medicina, Universidade Federal de Pelotas, 1997.

NUNES, M.A.A., RAMOS, D.C. Anorexia nervosa: classificação diagnóstica e quadro clínico. In: NUNES, M.A.A., APPOLINÁRIO, J.C., ABUCHAIM, A.L.G., COUTINHO, W. Transtornos alimentares e obesidade. Porto Alegre: ArtMed, 1998. p.21-30.

PESQUISA NACIONAL POR AMOSTRA DE DOMICÍLIOS, 1997. Brasília: IBGE. Disponível na Internet: <www.ibge.gov.br/informações/pnad>. Acesso em: 6 ago. 1998.

RATTNER, H. Globalização: em direção a "um mundo só?" In: BOLETIM do Programa Nacional LEAD - Liderança para o Meio Ambiente e Desenvolvimento Sustentável. São Paulo : [s.n.], 1995. (28p). (Mimeografado).

RIGOTTO, R.M. Saúde dos trabalhadores e meio ambiente em tempos de globalização e 
reestruturação produtiva. Fortaleza, 1998. 21 p. Mestrado (Saúde Pública) - Universidade Federal do Ceará, 1998.

ROBELL, S. A mulher escondida: a anorexia nervosa em nossa cultura. São Paulo : Summus, 1997. 141p.

SOCIEDADE BRASILEIRA DE PSIQUIATRIA CLÍNICA. Programa de educação sanitária: transtornos alimentares. São Paulo, 1993. 18p.

SOCIEDADE BRASILEIRA DE CIRURGIA PLÁSTICA. Números da Cirurgia Plástica no Brasil. São Paulo, 1999. s/p. (Mimeografado).
STRASBURGER, V.C. Os adolescentes e a mídia: impacto psicológico. Porto Alegre : Artmed, 1999. 157p.

SWIFT, R. Abaixo as dietas. Rio de Janeiro : Bertrand Brasil, 1997. 321p.

WOLF, N. O mito da beleza: como as imagens de beleza são usadas contra as mulheres. Rio de Janeiro : Rocco, 1992. 439p.

Recebido para publicação em 11 de maio de 2001 e aceito em 10 de janeiro de 2002. 